\title{
Aberrant expression of miR-153 is associated with the poor prognosis of cervical cancer
}

\author{
LI LIU $^{1}$, XIAOJING LAI ${ }^{2}$, CHANGJIN YUAN ${ }^{1}$, XIUWEI LV ${ }^{1}$, TAO YU ${ }^{1}$, \\ WENYU HE ${ }^{1}$, JIAOPING LIU ${ }^{1}$ and HAIMING ZHANG ${ }^{1}$ \\ ${ }^{1}$ Department of Oncology, Integrated Traditional Chinese and Western Medicine, The Central Hospital of Wuhan, \\ Tongji Medical College, Huazhong University of Science and Technology, Wuhan, Hubei 430012; \\ ${ }^{2}$ Applied Biotechnology Research Center, Hubei Engineering Research Center of Viral Vector, \\ Wuhan Institute of Bioengineering, Economic Development Zone of Yangluo, Wuhan, Hubei 430415, P.R. China
}

Received September 16, 2017; Accepted January 24, 2018

DOI: $10.3892 / \mathrm{ol} .2018 .8475$

\begin{abstract}
Previous studies have demonstrated that microRNAs (miRNAs) are frequently dysregulated in tumors and are associated with the initiation and progression of various types of cancer. miR-153 has been previously shown to have an anti-tumor effect in the majority of cancer types. However, to date, the expression status and function of miR-153 in cervical cancer (CC) remains unclear. In the present study, the expression of miR-153 in CC tissues and cell lines was examined, revealing that the expression of miR-153 was markedly downregulated in the $\mathrm{CC}$ tissues and cell lines investigated, when compared with matched noncancerous tissues and normal cervical epithelial cell line. Furthermore, ectopic expression of miR-153 by miR-153 mimic inhibited cell proliferation; however, transfection with the miR-153 inhibitor promoted the cell proliferation in CC cell lines. Finally, the results showed that the downregulation of miR-153 was associated with poor 5 -year over survival in $\mathrm{CC}$ patients and it could be regarded as an independent biomarker to predict the prognosis of CC patients. Collectively, these results indicated that miR-153 may function as a tumor suppressor in $\mathrm{CC}$, and it may be a potential novel therapeutic target for $\mathrm{CC}$.
\end{abstract}

\section{Introduction}

Cervical cancer (CC) is one of the most malignant female reproduction cancers in human, as well as the fourth most common cause of cancer-related morality in the world $(1,2)$. Globally, it was estimated that there were about 530,000 new

Correspondence to: $\mathrm{Dr} \mathrm{Li}$ Liu, Department of Oncology, Integrated Traditional Chinese and Western Medicine, The Central Hospital of Wuhan, Tongji Medical College, Huazhong University of Science and Technology, 26 Shengli Street, Jiang'an, Wuhan, Hubei 430012, P.R. China

E-mail: 1iliu8310@126.com

Key words: microR-153, cervical cancer, proliferation, prognosis diagnosed cases each year (1). In the meantime, approximately 135,000 causes were found in China, accounting for about $25 \%$ of all the new CC causes each year (3). Despite advances in the diagnosis and treatment methods for $\mathrm{CC}$ in recent years, unfortunately, the prognosis of CC patients remains poor (4-6). Therefore, exploring the molecular mechanisms related to the tumor initiation and progression of $\mathrm{CC}$ is of vital importance and might provide new biomarker to predict and improve the prognosis of CC patients.

Increasing researches have demonstrated that microRNAs (miRs) are a class of small, non-coding RNAs that play critical roles in various biological cellular processes, including cell proliferation, migration, differentiation, and apoptosis (7-9). In recent decades, dysregulation of miRs have been implicated in the development and malignant progression of human cancers and might be used as potential diagnostic or therapeutic targets for cancers (10-12). To date, over 2,500 miRs have been identified in human genome (13). Among numerous cancer-related miRs, miR-153 was recently found to be dysregulated in human cancers including breast cancer (14), ovarian cancer (15), osteosarcoma (16), esophageal squamous cell carcinoma (17), gastric cancer (18), pancreatic cancer (19), non-small-cell lung cancer (20), and colorectal cancer (21). Significantly, miR-153 expression was found upregulated in colorectal cancer but downregulated in the rest cancer types mentioned above (14-21), which implies that miR-153 plays a dual role in the progression of human cancers. However, up to now, the role of miR-153 in regulating human $\mathrm{CC}$ cells remains unexplored. Importantly, miR-153 was found dysregulated in gynecological tumors including breast cancer and ovarian cancer $(14,15)$. Therefore, it is worthwhile to investigate the clinical significance of miR-153 in CC.

In the present study, we found miR-153 was significantly downregulated in $\mathrm{CC}$ tissues and cell lines. Ectopic the expression of miR-153 inhibited cell proliferation in $\mathrm{CC}$ cell lines. Moreover, the downregulation of miR-153 in CC patients was associated with tumor size and lymph node metastasis. Furthermore, we revealed that the downregulation of miR-153 predicts the poor prognosis of CC patients. Taken together, our data revealed that miR-153 plays a tumor suppressor role 
in the progression of $\mathrm{CC}$ and may provide a novel potential therapeutic target for CC.

\section{Materials and methods}

Clinical tissue samples. This study was approved by the Ethics Committee of The Central Hospital of Wuhan. A total of 93 pairs of $\mathrm{CC}$ tissues and matched noncancerous tissues were collected at the Central Hospital of Wuhan between March 2008 and September 2011. The written informed consent has been obtained from all the enrolled patients. These enrolled patients did not receive any anti-tumor treatments prior to surgical resection. Tissues were immediately snap-frozen in liquid nitrogen after surgical resection, and stored in liquid nitrogen before usage. Clinicopathological parameters of the enrolled patients were collected at the beginning of the follow-up period and summarized in Table I. The overall survival time was calculated as the time between the date of surgery and the date of mortality or last follow-up for 60 months.

Cell lines and cell culture. The human CC cell lines including C-33A, HeLa, and SiHa were purchased from Type Culture Collection of the Chinese Academy of Sciences (Shanghai, China). These cells were cultured in Dulbecco's modified Eagle's medium (DMEM; Invitrogen; Thermo Fisher Scientific, Inc., Waltham, MA, USA) supplemented with $10 \%$ fetal bovine serum (FBS; HyClone; GE Healthcare Life Sciences, Logan, UT, USA), and $100 \mathrm{U} / \mathrm{ml}$ penicillin and $0.1 \mathrm{mg} / \mathrm{ml}$ streptomycin . The human cervical epithelial cell line End1 was purchased from American Type Culture Collection (ATCC, Manassas, VA, USA) and cultured in Keratinocyte-Serum Free medium (K-SFM; Invitrogen; Thermo Fisher Scientific, Inc.) with $0.1 \mathrm{ng} / \mathrm{ml}$ human recombinant EGF, $0.05 \mathrm{mg} / \mathrm{ml}$ bovine pituitary extract, and additional calcium chloride $44.1 \mathrm{mg} / \mathrm{l}$ (final concentration $0.4 \mathrm{mM}$ ). Cells were maintained in humidified incubator at $37^{\circ} \mathrm{C}$ containing $5 \%$ of $\mathrm{CO}_{2}$.

Cell transfection. The miR-153 mimic (5'-UUGCAUAGU CACAAAAGUGAUC-3'), miR-153 inhibitor (5'-AUCACU UUUGUGACUAUGCA-3') and negative control (miR-con) (5'-UAGCUUAUCAGACUGAUGUUGA-3') were purchased from Guangzhou RiboBio Co., Ltd., (Guangzhou, China). The cells were seeded into 6-well plates at a density of $3 \times 10^{5}$ cells/well. The synthetic miRNAs were transfected to the cultured cells using Lipofectamine 2000 (Invitrogen; Thermo Fisher Scientific, Inc.) according to the instructions provided by the manufacturer. Further analyses were performed $24 \mathrm{~h}$ post transfection.

Reverse transcriptase-quantitative polymerase chain reaction $(R T-q P C R)$. Total RNA from the cultured cell lines was isolated using TRIzol reagent (Beyotime Institute of Biotechnology, Haimen, China). RNA was reverse transcribed to cDNA using TaqMan miRNA reverse transcription kit (Applied Biosystems; Thermo Fisher Scientific, Inc.). RT-PCR was performed using PrimeScript miRNA RT-PCR kit (Takara Biotechnology Co., Ltd., Dalian, China) according to the manufacturer's instructions. The following procedures were used: 1 cycle at $95^{\circ} \mathrm{C}$ for $2 \mathrm{~min}, 40$ cycles at
Table I. Associations between microRNA-153 expression and clinicopathological features.

\begin{tabular}{|c|c|c|c|c|}
\hline \multirow[b]{2}{*}{ Variable } & \multirow[b]{2}{*}{ Cases (n) } & \multicolumn{2}{|c|}{$\begin{array}{c}\text { miR-153 } \\
\text { expression level }\end{array}$} & \multirow[b]{2}{*}{ P-value } \\
\hline & & $\underset{(\mathrm{n}=25) \%}{\text { High }}$ & $\begin{array}{c}\text { Low } \\
(\mathrm{n}=68) \%\end{array}$ & \\
\hline \multicolumn{5}{|c|}{ Age (years) } \\
\hline$>50$ & 45 & $12(26.7)$ & $33(72.3)$ & \multirow[t]{2}{*}{0.662} \\
\hline$<50$ & 48 & $13(27.1)$ & 35 (71.9) & \\
\hline \multicolumn{5}{|c|}{$\begin{array}{l}\text { Lymph node } \\
\text { metastasis }\end{array}$} \\
\hline Negative & 39 & $11(28.2)$ & $28(71.8)$ & \multirow[t]{2}{*}{0.039} \\
\hline Positive & 54 & $14(25.9)$ & $40(74.1)$ & \\
\hline \multicolumn{5}{|c|}{ Tumor size } \\
\hline$\geq 4 \mathrm{~cm}$ & 55 & $16(29.1)$ & $39(70.9)$ & \multirow[t]{2}{*}{0.018} \\
\hline$<4 \mathrm{~cm}$ & 38 & $9(23.7)$ & $29(76.3)$ & \\
\hline \multicolumn{5}{|c|}{ Clinical stage } \\
\hline I-II & 47 & $10(21.3)$ & 37 (78.7) & \multirow[t]{2}{*}{0.093} \\
\hline III & 46 & $15(32.6)$ & $31(67.4)$ & \\
\hline
\end{tabular}

miR-153, microRNA-153.

$95^{\circ} \mathrm{C}$ for $30 \mathrm{sec}$ and $58^{\circ} \mathrm{C}$ for $40 \mathrm{sec}$. U6 snRNA was used as an internal control to normalize the expression of miR-153. The primers for miR-153 and U6 snRNA used in this study were purchased from Guangzhou RiboBio Co., Ltd. and the detailed sequences were as follows: miR-153: Forward, 5'-TTGCATAGTCACAAAAGTGAT-3', Reverse, 5'-CAG TGCGTGTCGTGGAGT-3'; U6 snRNA: Forward, 5'-CTC GCTTCGGCAGCACATATACT-3', Reverse, 5'-ACGCTT CACGAATTTGCGTGTC-3'. The relative expression levels were calculated using the $2^{-\Delta \Delta C q}$ method (22).

Cell proliferation assay. To assess the cell proliferation rate, MTT method was employed. Briefly, the cells were cultured in 96-well plate at the density of $3 \times 10^{3}$ cells/well. At indicated time points $(0,24,48,72 \mathrm{~h}), 10 \mu 1$ MTT solution $(5 \mathrm{mg} / \mathrm{ml}$; Beyotime Institute of Biotechnology) was added to each well and incubated for additional $3 \mathrm{~h}$. Then, the supernatant was discarded followed by adding $200 \mu \mathrm{l}$ DMSO to dissolve the violet formazan crystals. After incubation for $2 \mathrm{~h}$, the optical density was measured at $570 \mathrm{~nm}$ using the Multiskan Spectrum equipment (Thermo Fisher Scientific, Inc.).

Statistical analysis. SPSS v16.0 software (SPSS, Inc., Chicago, IL, USA) was used for statistical analysis. To determine the significance of two groups and multiple groups, Student's $t$ test and one-way ANOVA were conducted respectively. Chi-square test was used to analyze the correlation between the expression of miR-153 and clinicopathological features. The Kaplan-Meier curve and log-rank test was used to analyze the overall survival of CC patients. Univariate and multivariate analyses with Cox proportional hazards model were used to identify the independent predictors for the prognosis of CC 

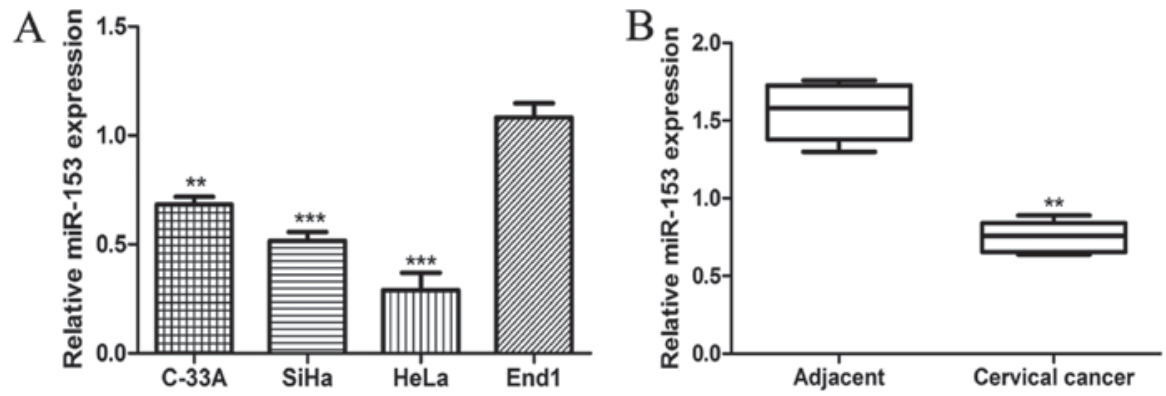

Figure 1. Downregulation of miR-153 in CC. (A) RT-qPCR was performed to analyze the expression of miR-153 in the CC cell lines C-33A, SiHa and HeLa, and the normal cervical epithelial cell line End1. (B) RT-qPCR was performed to analyze the expression of miR-153 in CC tissues and adjacent noncancerous tissues. ${ }^{* *} \mathrm{P}<0.01$ and ${ }^{* * *} \mathrm{P}<0.001$ vs. control (End1/Adjacent tissues). miR-153, microRNA-153; RT-qPCR, reverse transcription-quantitative polymerase chain reaction. $\mathrm{CC}$, cervical cancer.
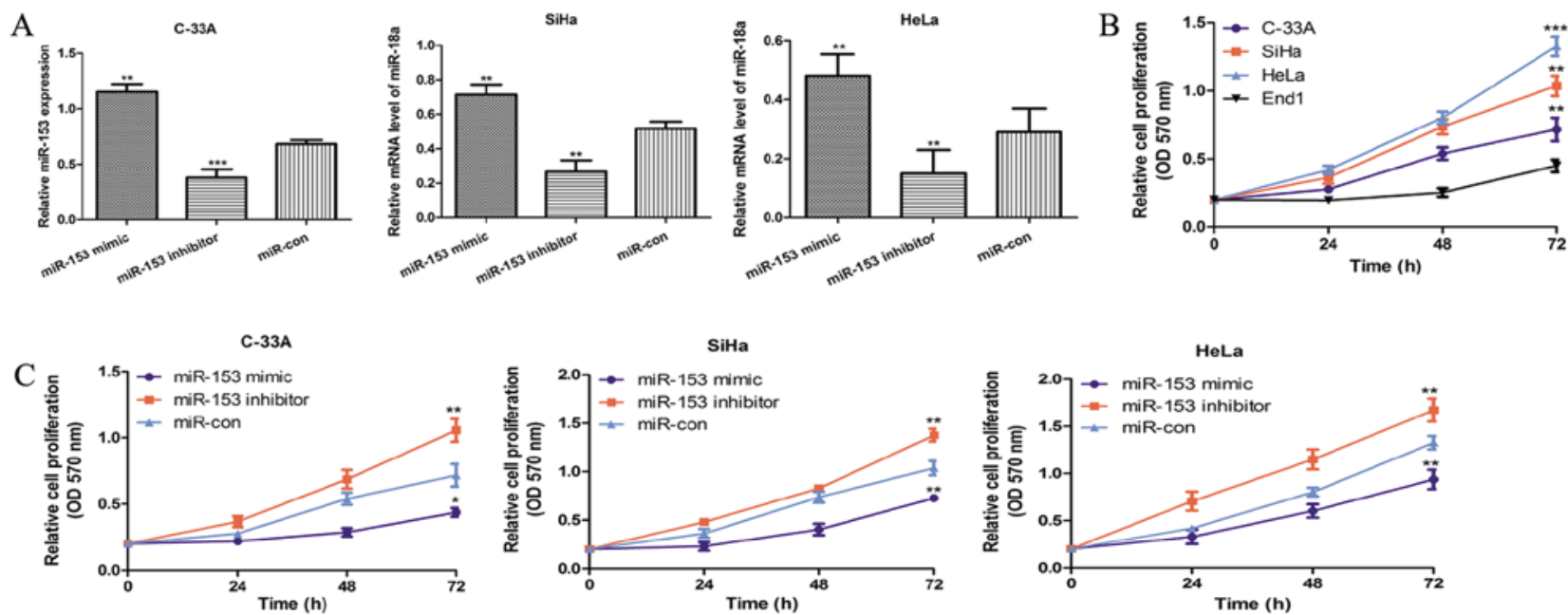

Figure 2. miR-153 overexpression inhibits the proliferation of CC cell lines. (A) Reverse transcription-quantitative polymerase chain reaction was performed to analyze the expression of miR-153 in the CC cell lines C-33A, SiHa and HeLa, following transfection with miR-153 mimic, miR-153 inhibitor and negative control. (B) An MTT assay was performed to analyze the cell proliferation of the CC cell lines (C-33A, SiHa and HeLa) and the normal cervical epithelial cell line End1. (C) An MTT assay was also performed to analyze the cell proliferation of the CC cell lines (C-33A, SiHa and HeLa) following transfection with miR-153 mimic, miR-153 inhibitor and negative control. ${ }^{*} \mathrm{P}<0.05,{ }^{* *} \mathrm{P}<0.01$ and ${ }^{* * * *} \mathrm{P}<0.001$ vs. control (End1/miR-con). miR-153, microRNA-153; CC, cervical cancer; miR-con, negative control miRNA; OD $570 \mathrm{~nm}$, optical density at $570 \mathrm{~nm}$.

patients. Data were presented as the mean \pm SD. $\mathrm{P}<0.05$ was considered to indicate a statistically significant difference.

\section{Results}

MiR-153 is downregulated in CC tissues and cell lines. We measured the expression of miR-153 in CC cell lines (C-33A, $\mathrm{HeLa}$, and $\mathrm{SiHa}$ ) and normal cervical epithelial cell line End1 by RT-qPCR. As presented in Fig. 1A, the expression of miR-153 was significantly reduced in CC cell lines investigated compared with that in normal cervical epithelial cell line (all $\mathrm{P}<0.01$ ). To further confirm the significance of miR-153 expression in CC, the expression level of miR-153 in 93 paired $\mathrm{CC}$ tissues and adjacent normal tissues was measured by the same method. We found the miR-153 expression was significantly lower in $\mathrm{CC}$ tissues compared with in adjacent normal tissues $(\mathrm{P}<0.01$; Fig. $1 \mathrm{~B})$, which was consistent with the observations on $\mathrm{CC}$ cell lines and normal cervical epithelial cell line. These 93 CC patients were then classified into two groups based on the expression level of miR-153: Namely high miR-153 expression group and low miR-153 expression group. The 75 th percentile of $2^{-\Delta \Delta \mathrm{Cq}}$ was used as the cut-off point (0.72) for patients with high or low miR-153 expression (23).

MiR-153 inhibits the proliferation of CC cell lines in vitro. To explore the role of miR-153 in CC cells, miR-153 expression level was altered with miR-153 mimic and inhibitor. RT-qPCR showed that miR-153 expression was significantly enhanced in all the investigated CC cell lines transfected with miR-153 mimic compared with those transfected with miR-con (all $\mathrm{P}<0.01$; Fig. 2A). Conversely, the miR-153 inhibitor transfection could reduce the expression of miR-153 in the CC cell lines investigated (all $\mathrm{P}<0.01$; Fig. 2A). Cell proliferation rate was measured using MTT assay, the cell proliferation of CC cell lines was significantly higher than that of normal cervical epithelial cell (all $\mathrm{P}<0.01$; Fig. 2B). Following, the cell proliferation of CC cell lines transfected with miRNAs was also measured by the same method. As shown in Fig. 2C, we found the CC cells transfected with miR-153 mimic showed obvious growth inhibition, while those transfected with miR-153 inhibitor showed obvious growth stimulation (all $\mathrm{P}<0.05$ ). 
Table II. Univariate and multivariate analyses of overall survival.

\begin{tabular}{|c|c|c|c|c|c|c|}
\hline \multirow[b]{2}{*}{ Variable } & \multicolumn{2}{|c|}{ Univariate analysis } & \multirow[b]{2}{*}{ P-value } & \multicolumn{2}{|c|}{ Multivariate analysis } & \multirow[b]{2}{*}{ P-value } \\
\hline & $\mathrm{HR}$ & $95 \% \mathrm{CI}$ & & HR & $95 \%$ CI & \\
\hline miR-153 & 2.062 & $1.080-3.936$ & 0.028 & 2.080 & $1.096-3.949$ & 0.025 \\
\hline Age & 1.798 & $0.870-3.716$ & 0.113 & - & - & - \\
\hline Lymph node metastasis & 1.981 & $1.103-3.873$ & 0.046 & 2.001 & $1.030-3.889$ & 0.041 \\
\hline Tumor size & 2.021 & $1.047-3.904$ & 0.036 & 2.043 & $1.065-3.922$ & 0.032 \\
\hline Clinical stage & 1.896 & $0.945-3.804$ & 0.072 & - & - & - \\
\hline
\end{tabular}

HR, hazard ratio; CI, confidence interval; miR-153, microRNA-153.

Clinical significance of miR-153 expression in CC. To investigate the clinical significance of miR-153, we assessed the association between miR-153 expression and clinicalpathological features. The results revealed that low miR-153 expression was associated with tumor size $(\mathrm{P}=0.018)$, lymph node metastasis $(\mathrm{P}=0.039)$ but not related to age $(\mathrm{P}=0.662)$, clinical stage $(\mathrm{P}=0.093)$ in $\mathrm{CC}$ patients (Table I). The Kaplan-Meier curve and log-rank test was employed to analyze the effect of miR-153 expression on 5-year overall survival of the 93 enrolled CC patients. We found the patients with high miR-153 expression $(n=25)$ live longer than those with low miR-153 expression $(n=68)(P=0.037$; Fig. 3). Additionally, multivariate analysis indicated that miR-153 expression was an independent predictor for the overall survival in CC patients $(\mathrm{P}=0.025$; Table II). Taken together, there was a strong correlation between low miR-153 expression and poor outcomes in CC patients.

\section{Discussion}

miRNAs function mainly through complementary binding to the 3'-UTR of target gene which can induce the degradation of its mRNA, or suppress gene transcription to reduce the expression levels of its target genes (24-26). Many studies have confirmed that miRNAs were critical players in the initiation and progression of human cancers including CC $(27,28)$. For $\mathrm{CC}$ patients, the overall survival has significantly improved in the past decade due to the usage of HPV vaccination and improvement of therapeutics methods but it is still undesirable $(4,5)$. Therefore, it is of great importance to understand the molecular mechanisms underlying the progression of $\mathrm{CC}$, which are important for developing novel therapeutic strategies for patients with CC.

Although documented evidence indicates that miR-153 can function as either oncogene or tumor-suppressor in cancers, the role of miR-153 in regulating CC cells remains unexplored (14-21). In the present study, the miR-153 expression was found to be downregulated in CC tissues and cell lines. The cell proliferation rate analysis results demonstrated that the cell proliferation rate in CC cells was higher than in normal cervical epithelial cell line. To further elucidate the effect of miR-153 on the progression of CC, the synthetic miRNAs were introduced into the $\mathrm{CC}$ cell lines. We discovered that the overexpression of miR-153 diminished but the

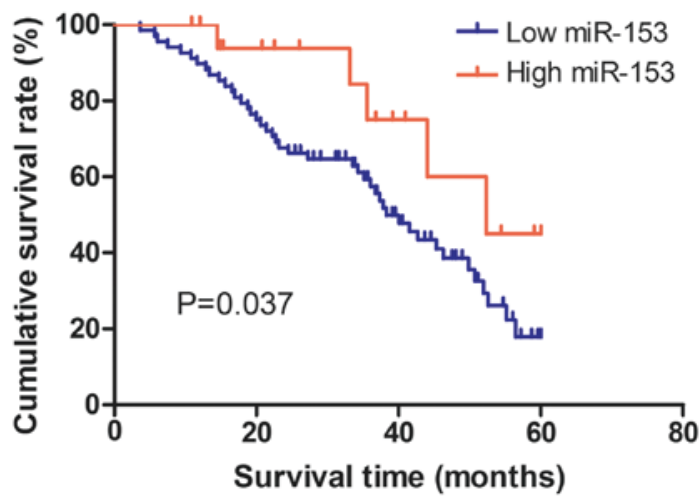

Figure 3. Low expression levels of miR-153 are associated with the poor prognosis of patients with CC. Patients were divided into the miR-153 low group ( $n=68)$ and high group $(n=25)$ to analyze the cumulative survival rate. miR-153, microRNA-153; CC, cervical cancer.

downregulate miR-153 expression increased the proliferation rate in the $\mathrm{CC}$ cells investigated. The above findings indicated that miR-153 functions as tumor-suppressor in $\mathrm{CC}$ and inhibits CC progression partly through cell proliferation inhibition. The progression of $\mathrm{CC}$ is a complex pathological process in which proliferation and apoptosis of CC cells serves an important role (29). The proliferation and apoptosis of CC cells are regulated by multiple molecules, including phosphatase and tension homolog (PTEN) (30), miR-21 (31), miR-940 (32), and DJ-1 (33). Therefore, the aberrant expressed status of miR-153 and the involvement of miR-153 in $\mathrm{CC}$ proliferation process highlighted the importance of miR-153 in CC.

Then, we analyzed the 5-year overall survival rate of the recruited CC patients. We found the low expression of miR-153 indicates a poor 5-year survival. Following, we found the low miR-153 expression was related to tumor size and lymph node metastasis. The univariate and multivariate analyses demonstrated that low miR-153 expression was an independent predictor for poor overall survival of patients with CC.

In conclusion, we provided evidence that miR-153 exert its tumor suppressor potential by inhibiting cell proliferation. Meanwhile, there was a strong correlation between low miR-153 expression and poor outcomes in CC patients, indicating miR-153 could potentially serve as a therapeutic target for CC. 


\section{Acknowledgements}

The present study was supported by National Natural Science Foundation of China (grant no. 31500840); Health and Family Planning Commission of Wuhan Province (grant no. WZ17Z03).

\section{References}

1. Torre LA, Bray F, Siegel RL, Ferlay J, Lortet-Tieulent J and Jemal A: Global cancer statistics, 2012. CA Cancer J Clin 65: 87-108, 2015.

2. Siegel RL, Miller KD and Jemal A: Cancer Statistics, 2017. CA Cancer J Clin 67: 7-30, 2017.

3. Wang JM, Ju BH, Pan CJ, Gu Y, Li MQ, Sun L, Xu YY and Yin LR: MiR-214 inhibits cell migration, invasion and promotes the drug sensitivity in human cervical cancer by targeting FOXM1. Am J Transl Res 9: 3541-3557, 2017.

4. Ellenson LH and Wu TC: Focus on endometrial and cervical cancer. Cancer Cell 5: 533-538, 2014.

5. Yoshikawa H: Progress in the World and challenges in Japan on HPV vaccination for cervical cancer prevention. Gan To Kagaku Ryoho 37: 971-975, 2010 (In Japanese).

6. Ghebre RG, Grover S, Xu MJ, Chuang LT and Simonds H: Cervical cancer control in HIV-infected women: Past, present and future. Gynecol Oncol Rep 21: 101-108, 2017.

7. Calin GA and Croce CM: MicroRNA-cancer connection: The beginning of a new tale. Cancer Res 66: 7390-7394, 2006.

8. Bartel DP: MicroRNAs: Genomics, biogenesis, mechanism, and function. Cell 116: 281-297, 2004.

9. Garzon R, Calin GA and Croce CM: MicroRNAs in cancer. Annu Rev Med 60: 167-179, 2009.

10. Lu J, Getz G, Miska EA, Alvarez-Saavedra E, Lamb J, Peck D, Sweet-Cordero A, Ebert BL, Mak Rh, Ferrando AA, et al: MicroRNA expression profiles classify human cancers. Nature 435: 834-838, 2005.

11. Iorio MV and Croce CM: MicroRNA dysregulation in cancer: Diagnostics, monitoring and therapeutics. A comprehensive review. EMBO Mol Med 9: 852, 2017.

12. Esquela-Kerscher A and Slack FJ: Oncomirs-microRNAs with a role in cancer. Nat Rev Cancer 6: 259-269, 2006.

13. Kozomara A and Griffths-Jones S: miRBase: Annotating high confdence microRNAs using deep sequencing data. Nucleic Acids Res 42: D68-D73, 2014.

14. Wu XW, Li L, Li Y and Liu ZH: MiR-153 promotes breast cancer cell apoptosis by targeting HECTD3. Am J Cancer Res 6: $1563-1571,2016$

15. Zhou J, Xie M, Shi Y, Luo B, Gong G, Li J, Wang J, Zhao W, $\mathrm{Zi} \mathrm{Y,} \mathrm{Wu} \mathrm{X} \mathrm{and} \mathrm{Wen} \mathrm{J:} \mathrm{MicroRNA-153} \mathrm{functions} \mathrm{as} \mathrm{a} \mathrm{tumor}$ suppressor by targeting SET6 and ZEB2 in ovarian cancer cells. Oncol Rep 34: 111-120, 2015.

16. Niu GF, Li B, Sun L and An CG: MicroRNA-153 inhibits osteosarcoma cells proliferation and invasion by targeting TGF- $\beta 2$. PLoS One 10: e0119225, 2015.

17. Zuo J, Wang D, Shen H, Liu F, Han J and Zhang X: MicroRNA-153 inhibits tumor progression in esophageal squamous cell carcinoma by targeting SNAI1. Tumor Biol, 2016 (Epub ahead of print).
18. Wang $\mathrm{Z}$ and Liu C: MiR-153 regulates metastasis of gastric cancer through Snail1. Tumor Biol, 2015 (Epub ahead of print).

19. Liu F, Liu B, Qian J, Wu G, Li J and Ma Z: miR-153 enhances the therapeutic effect of gemcitabine by targeting Snail in pancreatic cancer. Acta Biochim Biophys Sin (Shanghai) 49: 520-529, 2017.

20. Shan N, Shen L, Wang J, He D and Duan C: MiR-153 inhibits migration and invasion of human non-small-cell lung cancer by targeting ADAM19. Biochem Biophys Res Commun 456: 385-391, 2015.

21. Zhang L, Pickard K, Jenei V, Bullock MD, Bruce A, Mitter R, Kelly G, Paraskeva C, Strefford J, Primrose J, et al: miR-153 supports colorectal cancer progression via pleiotropic effects that enhance invasion and chemotherapeutic resistance. Cancer Res 73: 6345-6347, 2013.

22. Schmittgen TD and Livak KJ: Analyzing real-time PCR data by the comparative C(T) method. Nat Protoc 3: 1101-1108, 2008

23. Chen ZL, Zhao XH, Wang JW, Li BZ, Wang Z, Sun J, Tan FW, Ding DP, Xu XH, Zhou F, et al: microRNA-92a promotes lymph node metastasis of human esophageal squamous cell carcinoma via E-cadherin. J Biol Chem 286: 10725-10734, 2011.

24. Wongfieng W, Jumnainsong A, Chamgramol Y, Sripa B and Leelayuwat C: 5'-UTR and 3'-UTR regulation of MICB expression in human cancer cells by novel microRNAs. Gene (Basel) 8: E213, 2017.

25. Biegel JM, Henderson E, Cox EM, Bonenfant G, Netzband R, Kahn S, Eager R and Pager CT: Cellular DEAD-box RNA helicase DDX6 modulates interaction of miR-122 with the 5 untranslated region of hepatitis $\mathrm{C}$ virus RNA. Virology 507: 231-241, 2017.

26. Xiao Y, Li X, Wang H, Wen R, He J and Tang J: Epigenetic regulation of miR-129-2 and its effects on the proliferation and invasion in lung cancer cells. J Cell Mol Med 19: 2172-2180, 2015.

27. Gregory RI and Shiekhattar R: MicroRNA biogenesis and cancer. Cancer Res 65: 3509-3512, 2005.

28. Calin GA and Croce CM: MicroRNA signatures in human cancers. Nat Rev Cancer 6: 857-866, 2006.

29. Xu L, Xu Q, Li X and Zhang X: MicroRNA-21 regulates the proliferation and apoptosis of cervical cancer cells via tumor necrosis factor- $\alpha$. Mol Med Rep 16: 4659-4663, 2017.

30. Feng Y, Zou W, Hu C, Li G, Zhou S, He Y, Ma F, Deng C and Sun L: Modulation of CASC2/miR-21/PTEN pathway sensitizes cervical cancer to cisplatin. Arch Biochem Biophys 623-624: 20-30, 2017.

31. Du G, Gao D and Meng L: miR-21 inhibitor suppresses cell proliferation and colony formation regulating the PTEN/AKT pathway and improves paclitaxel sensitivity in cervical cancer cells. Mol Med Rep 15: 2713-2719, 2017.

32. Su K, Wang CF, Zhang Y, Cai YJ, Zhang YY and Zhao Q: miR-940 upregulation contributes to human cervical cancer progression through p27 and PTEN inhibition. Int J Oncol, 2017 (Epub ahead of print).

33. Wang $\mathrm{H}$ and Gao W: DJ-1 expression in cervical carcinoma and its effects on cell viability and apoptosis. Med Sci Monit 22: 2943-2949, 2016.

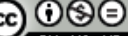

This work is licensed under a Creative Commons Attribution-NonCommercial-NoDerivatives 4.0 International (CC BY-NC-ND 4.0) License. 